\title{
Instituições políticas domésticas e cooperação internacional na díade Chile-Uruguai (1973-2000)
}

\author{
Pedro Diniz Rocha*
}

\section{Resumo}

O objetivo deste artigo é o de analisar de forma comparativa os níveis de cooperação internacional na díade Chile-Uruguai em dois momentos distintos: entre 1973 e 1985, quando a díade era autocrática, e entre 1990 e 2000, quando a díade se tornou democrática. A partir do estudo de caso berfore-and-after se pretende testar a hipótese de que as Instituições Políticas Domésticas podem explicar os níveis de cooperação em uma díade. De modo a realizá-lo foram levantados os tratados assinados e ratificados por Chile e Uruguai entre 1973 e 2000, disponíveis no acervo online da Biblioteca del Congreso Nacional de Chile. Após, realizou-se pesquisa documental onde as áreas temáticas e o modelo de cooperação adotado foram destacados. Enfim, em ordem a julgar a intensidade da cooperação nos dois períodos destacados, foi comparado o número bruto de tratados firmados, as áreas temáticas onde se estabeleceram os acordos e o modelo de cooperação adotado.

Palavras-chave: Instituições Políticas Domésticas - Cooperação Internacional - Chile - Uruguai

\section{Domestic political institutions and international cooperation in the dyad Chile-Uruguay (1973-2000)}

\begin{abstract}
The main goal of this article is to analyze comparatively the levels of international cooperation in the dyad Chile-Uruguay in two distinctive moments: between 1973 and 1985, when the dyad was autocratic, and between 1990 and 2000, when the dyad became democratic. The before-and-after study case delineated is expected to test the hypothesis that Domestic Political Institutions can explain the levels of cooperation in a dyad. In order to conduct it, treaties signed and ratified by Chile and Uruguay between 1973 and 2000 and available at the Biblioteca del Congreso Nacional de Chile online archive were collected. After, a documental research was performed signaling the issue-areas and the model of cooperation (bilateral or multilateral) of the accords. Finally, in order to judge the intensity of cooperation in the two underlined periods, it was compared the raw numbers of treaties, its issue-areas and the model of cooperation adopted.
\end{abstract}

Key-words: Domestic Political Institutions - International Cooperation - Chile - Uruguay

\footnotetext{
* Mestrando em Relações Internacionais, Pontifícia Universidade Católica de Minas Gerais (PUC-Minas, Brasil). E-mail: pedro.diniz.rocha@gmail.com
} 


\section{Instituciones políticas domésticas y cooperación internacional en la díada Chile-Uruguay (1973-2000)}

\section{Resumen}

El objetivo de este artículo es analizar de manera comparada los niveles de cooperación internacional en la díada Chile-Uruguay en dos momentos distintos: entre 1973 y 1985, cuando los dos Estados eran autocráticos, y entre 1990 y 2000 cuando los Estados se transformaron en democracias. A partir de un estudio de caso before-and-after se espera testear la hipótesis de trabajo de que las Instituciones Políticas Domésticas pueden explicar el nivel de cooperación internacional entre dos Estados. En vistas a la realización de este trabajo, se realizó el relevamiento de los tratados firmados y ratificados por Chile y Uruguay entre 1973 y 2000 , disponibles en el acervo online de la Biblioteca del Congreso Nacional de Chile. Después, se realizó una investigación documental señalando las áreas temáticas y el modelo de cooperación (bilateral o multilateral) de los acuerdos. Por fin, a fin de juzgar el nivel de cooperación en los dos períodos, se comparó el número bruto de tratados, sus áreas temáticas y el modelo de cooperación adoptado.

Palabras-Clave: Instituciones Políticas Domésticas - Cooperación Internacional - Chile - Uruguay

TRABAJO RECIBIDO: 08/08/2018 TRABAJO ACEPTADO: 10/10/2018 


\section{Introdução}

O que é e quais são as possibilidades de cooperação internacional em um Sistema de Estados caracterizado pela anarquia é tema central dentro das Relações Internacionais (RI), no geral, e da Análise de Política Externa (APE), em particular. Em ordem a enfrentar dito problema partir-se-á de perspectiva que se afasta a grosso modo da tradicional escola realista das RI em dois pontos principais. Por um lado, ao considerar ser possível a cooperação internacional tanto em temas de alta política (high politics), como segurança e defesa, quanto em temas de baixa política (low politics), como comércio e meio ambiente, apesar das dificuldades intrínsecas a cada área temática; por outro lado, ao flexibilizar pressuposto do Estado como ator unitário e abrir a caixa preta da política doméstica, considerando a influência das instituições políticas e das preferências e interesses de atores domésticos no processo de formulação e no resultado da política externa (Milner, 1997:3; Putnam, 2010:151). Isto é, em termos de Putnam (2010:151), o Estado será tratado não como “"o Estado, ele', mas sim 'o Estado, eles"” e variável em nível doméstico (instituições políticas domésticas) será destacada para compreensão de resultado em nível internacional (cooperação internacional) (Leeds, 1999).

Dito isto, a pergunta de partida deste artigo pode ser estruturada da seguinte maneira: de que maneira características das Instituições Políticas Domésticas podem explicar os níveis de cooperação internacional em uma díade? A hipótese de trabalho adotada é a de que as características das Instituições Políticas Domésticas podem explicar o nível de cooperação internacional em uma díade na medida em que afetam de forma conjunta a expectativa dos atores de que não vai haver defecção e de que os acordos uma vez ratificados serão cumpridos. Díades democráticas tendem a cooperar mais e em um maior número de issue-areas se comparado a díades autocráticas, na medida em que a presença de instituições e procedimentos domésticos nos quais a população possa expressar livremente suas preferências e a existência de constrangimentos estruturais institucionalizados ao exercício de poder do executivo leva a expectativa de que seus compromissos são críveis e de que não vai haver defecção uma vez ratificados os acordos.

O estudo da cooperação internacional na díade Chile-Uruguai entre 1973 e 2000 é mister para o teste da hipótese de trabalho na medida em que na década de 1970 ambos os Estados se tornam autocracias; na década de 1980, ambos os países passam por processo de democratização; e, em consequência, na década de 1990 a díade é caracterizada por um contexto onde ambas as partes são democracias.

De modo a testar a hipótese de trabalho a análise se dará então de forma comparada em termos longitudinais - o caso transformar-se-á em um estudo de caso before-and-after. O marco para a divisão dos subcasos (o evento fulcral ou pivotal) será a democratização dos dois países na década de 1980. A hipótese será considerada fortalecida caso for possível demonstrar que entre os anos de 1973 e 1985 (quando a díade era autocrática) os dois países cooperavam de forma menos intensa se comparado a década de 1990 (quando a díade se tornou democrática).

O texto será dividido em três partes principais: na primeira seção serão sublinhados os argumentos teóricos que sustentam a hipótese de trabalho levantada; na segunda seção será delineado o desenho de pesquisa do artigo; enfim, na terceira seção será realizada análise comparada before-and-after da cooperação internacional na díade Chile-Uruguai entre os anos de 1973 e 1985 e a década de 1990. Ao final do artigo serão apresentadas considerações finais constando os resultados obtidos na análise e as implicações do estudo de caso para pesquisas futuras. 


\section{1 - Instituições Políticas Domésticas e Cooperação Internacional}

Como ponto de partida para o argumento teórico a ser delineado, a cooperação internacional será compreendida em termos de Keohane (1984:51) como todo "ajuste em cursos de ação tendo em vista as preferências atuais ou antecipadas de outros a partir de processo de coordenação política" (Keohane, 1984:51) ${ }^{1}$. Segue-se a definição que a coordenação política se faz importante na medida em que é por ela que as consequências negativas da ação unilateral aos interesses e as preferências da segunda parte podem ser reduzidas ou eliminadas (Milner, 1997:5). Além disso, sua presença na definição é fundamental para evidenciar o caráter negociado e político da cooperação internacional, o distanciando do conceito de harmonia de interesses onde naturalmente a ação de uma das partes maximiza os ganhos da outra sem necessidade de coordenação política (Keohane, 1984:51).

A partir da definição de Keohane (1984:51), Milner (1997:5) aponta dois elementos fundamentais. Em primeiro lugar, a escolha por cooperar ou não cooperar é pautada por determinados objetivos, interesses e preferências dos atores políticos domésticos relevantes ao processo de tomada de decisão em política externa. Em segundo lugar, ao decidir pela cooperação os atores políticos esperam receber ganhos ou benesses. O que implica em alguns casos a percepção de que a cooperação internacional não seja o curso de ação que maximiza seus interesses ou preferências, isto é, que os custos do desacordo são menores que os benefícios da coordenação política (Leeds, 1999:981).

Dessa maneira, pode-se dizer que a decisão por cooperar é tomada a partir da apreensão dos atores acerca dos custos e/ou benefícios de um acordo. A partir de Leeds (1999:980) os custos do acordo em parte se condicionam pela expectativa de que seus termos serão cumpridos uma vez tendo sido instituídos e, portanto, são parte importante para a compreensão da cooperação internacional. Isto significa dizer que "os atores não formarão arranjos que esperam ser quebrados, já que isso será sempre mais custoso que o status quo" (Leeds, 1999:984)². Tem-se como pressuposto, então, que a possibilidade de cooperação internacional em um sistema de Estados marcado pela anarquia depende em parte da capacidade dos lados de assegurarem o cumprimento dos acordos uma vez instituídos (ou seja, sua credibilidade) e de absorverem os custos de potencial defecção de seus pares (ou seja, sua flexibilidade) (Leeds, 1999: 980).

$\mathrm{O}$ argumento delineado é o de que características intrínsecas às instituições políticas domésticas influenciam tanto a credibilidade quanto a flexibilidade dos Estados e, dessa maneira, afetam a possibilidade de cooperação internacional em uma díade (Leeds, 1999). Em primeiro lugar, Estados nos quais as instituições políticas domésticas garantem à população liberdade para expressar suas idéias e preferências sobre lideranças e políticas públicas tendem a apresentar maior credibilidade e menor nível de flexibilidade. Isto porque, nesse contexto, resultados em nível internacional tem consequências distributivas e eleitorais domesticamente (Milner, 1997:16). Durante as negociações grupos políticos domésticos desenvolvem preferências e interesses sobre o tema em pauta e uma vez tendo sido instituídos os termos do acordo, ajustam seu comportamento de modo a maximizar os benefícios da política adotada pelo governo (Gaubatz, 1996:123; Leeds, 1999:987). Dessa maneira, os líderes (agentes) representantes da população e de determinados grupos políticos domésticos (principais) e pouco dispostos a arcar com os custos eleitorais de quebrar compromissos tendem a se comprometer de forma mais firme aos ditames dos acordos (Fearon, 1994:581; Leeds, 1999:987).

\footnotetext{
1 "Cooperation occurs when actors adjust their behavior to the actual or anticipated preferences of others, through a process of policy coordination” (Keohane, 1984:51), tradução livre.

2 "Actors will not form an agreement that they expect will be broken; doing so would always be more costly than the status quo” (Leeds, 1999:984), tradução livre
} 
Em segundo lugar, Estados nos quais as instituições políticas domésticas apresentam constrangimentos estruturais ao exercício do poder executivo, seja pela presença de check and balances bem delineados ou mecanismos padronizados de tomada de decisão em política externa, tendem também a apresentar maior credibilidade e menor nível de flexibilidade (Leeds, 1999:988). A divisão de poderes e a necessidade de ratificação de tratados pelo legislativo, por exemplo, influenciam a habilidade do gabinete de firmar compromissos em nível internacional, dificultam sua capacidade de reverter acordos uma vez instituídos e facilitam o monitoramento da adesão aos seus termos por parte da segunda parte (Cowhey, 1993:300).

Por detrás do disposto acerca das características das instituições políticas domésticas, subjaz definição procedimental de democracia proposta pelo projeto Polity IV. Como apresentado em seu User's Manual, democracias podem ser identificadas a partir de três elementos essenciais e interdependentes:

em primeiro lugar a presença de instituições e procedimentos pelos quais os cidadãos podem expressar de maneira efetiva as suas preferências sobre as lideranças políticas e diferentes políticas públicas. Em segundo lugar pela existência de constrangimentos institucionalizados ao exercício do poder pelo executivo. Em terceiro lugar, pela garantia de liberdades civis e políticas a todos os cidadãos em seu dia-a-dia (Marshall, Gurr e Jaggers, 2017:14) ${ }^{3}$.

Dessa maneira, argumenta-se que democracias e autocracias, na medida em que variam as características de suas instituições políticas domésticas, apresentam comparativamente diferentes níveis de credibilidade e flexibilidade, que por sua vez influenciam a capacidade dos Estados de cooperar em nível internacional (Leeds, 1999).

Por um lado, democracias tendem a apreciar maior nível de credibilidade, na medida em que contam com a presença de instituições políticas domésticas mais estáveis, que estruturalmente constrangem os poderes do gabinete e que submetem os líderes a prestar contas à sociedade civil (Fearon, 1994:578; Leeds, 1999:981). No entanto, as mesmas características que tornam Estados democráticos mais críveis os transformam em menos flexíveis, sendo mais laborioso o processo de ajuste uma vez os acordos instituídos e, portanto, maiores os custos de estabelecer compromissos em primeiro lugar (Gaubatz, 1996:121; Leeds, 1999:989). Por outro lado, autocracias tendem a ser menos críveis, visto que não há grandes constrangimentos institucionais ao exercício de poder por parte do gabinete, seja pela ausência de checks and balances ou da necessidade, em parte, de prestar contas à sociedade civil. Apesar disso, são mais flexíveis, sendo os líderes mais fácil e rapidamente capazes de ajustar ou modificar políticas já instituídas. Em consequência, menores os custos do compliance se comparado àqueles enfrentados pelas democracias (Leeds, 1999:988).

A partir do quadro teórico-conceitual delineado e de Leeds (1999:991), conclui-se então que (i) "díades democráticas tendem a se engajar comparativamente em maiores níveis de cooperação" ". Isso porque, apesar das partes serem pouco flexíveis, ambas são críveis, o que diminui os riscos da defecção da outra parte e, portanto, os custos da cooperação internacional. Além disso, que (ii) "díades autocráticas tendem a se engajar em níveis maiores de cooperação se comparadas a díades compostas por uma democracia e uma autocracia", e menores se comparadas

\footnotetext{
3 "One is the presence of institutions and procedures through which citizens can express effective preferences about alternative policies and leaders. Second is the existence of institutionalized constraints on the exercise of power by the executive. Third is the guarantee of civil liberties to all citizens in their daily lives and in acts of political participation" (Marshall, Gurr e Jaggers, 2017:14), tradução livre.

4 "Jointly democratic dyads will engage in comparatively high levels of cooperation" (Leeds, 1999:991), tradução livre.

5 "Jointly autocratic dyads will engage in higher levels of cooperation than dyads composed of one democracy and one autocracy” (Leeds, 1999:991), tradução livre.
} 
a díades democráticas. Isso em razão de que, apesar das partes serem pouco críveis, ambas são bastante flexíveis, o que reduz, em partes, os custos da cooperação internacional. Por fim, que (iii) "díades compostas por uma democracia e uma autocracia enfrentam os maiores impedimentos a cooperação e, portanto, tendem a apresentar menor nível de cooperação do que aquelas compostas por Estados com semelhantes instituições políticas domésticas" ". Isso pois, embora democracias sejam bastante críveis e autocracias em grande parte flexíveis, os custos do acordo em especial para o Estado democrático tendem a ser grandes, já que nada garante o cumprimento dos termos por parte da autocracia e, por seu turno, suas instituições políticas domésticas não lhe conferem flexibilidade.

\section{2 - Desenho de Pesquisa}

De modo a testar a hipótese de trabalho delineada será realizado um estudo de caso. Como apontam George e Bennett (2004:18), os casos escolhidos devem sempre corresponder ao objeto ou fenômeno que se pretende analisar e a pergunta "esse evento é um caso de...?" é central para a sua seleção. Aqui, pretende-se apreender se as instituições políticas domésticas importam para compreender diferentes níveis de cooperação internacional em uma díade. Dessa maneira, o caso a ser escolhido deve, impreterivelmente, enfrentar esse problema. Tem-se então, que o estudo da cooperação internacional na díade Chile-Uruguai entre 1973 e 2000 é mister para o teste da hipótese de trabalho na medida em que na década de 1970 ambos os Estados se tornam autocracias; na década de 1980, ambos os países passam por processo de democratização; e, em consequência, na década de 1990 a díade é caracterizada por um contexto onde ambas as partes são democracias.

O estudo de caso escolhido será construído como um caso before-and-after. De acordo com McDonald (2010:51) ${ }^{7}$ "um estudo de caso before-and-after é composto por fenômeno ou experiência envolvendo indivíduos, grupos, instituições, com resultados antes e depois de um evento de interesse" e, portanto, a pesquisa deve identificar um evento fulcral ou pivotal e assimilar e comparar os aspectos do caso anteriores e posteriores a tal. A análise before-and-after possibilita, então, utilizar o método comparativo ${ }^{8}$ dentro de um único estudo de caso ao dividi-lo em dois subcasos relativamente independentes. Em relação a cooperação internacional na díade ChileUruguai (1973-2000), o marco para a divisão dos subcasos será a democratização dos dois países na década de 1980. A hipótese será considerada fortalecida caso for possível demonstrar que entre os anos de 1973 e 1985 (quando a díade era autocrática) os dois países cooperavam de forma menos intensa se comparado a década de 1990 (quando a díade se tornou democrática).

Em relação à operacionalização das variáveis, por um lado tem-se como variável independente às instituições políticas domésticas. Os Estados serão classificados ao longo do período como democracias ou autocracias de acordo com definição procedimental proposta pelo projeto Polity $I V$. O projeto se utiliza de três elementos principais para identificar democracias ou autocracias: i) a existência de instituições e procedimentos pelos quais os indivíduos possam expressar suas preferências (exemplo: eleições livres e regulares); ii) a existência de constrangimentos estruturais ao exercício do poder executivo (exemplo: divisão de poderes); iii) a

\footnotetext{
6 "Dyads composed of one democracy and one autocracy will find the impediments to cooperation strongest; they will engage in lower levels of cooperation than states with similar internal structures" (Leeds, 1999:991), tradução livre.

7 "A before-and-after case study describes a single example of a phenomenon or experience involving individual, group, institutional, or social responses before and after an event of interest" (McDonald, 2010:51), tradução livre.

8 Ver Przeworski e Teune (1970) e Sartori (1994).
} 
existência de garantias constitucionais e reais (práticas) as liberdades civis e políticas (Marshall, Gurr e Jaggers, 2017:14).

Por outro lado, tem-se como variável dependente a cooperação internacional. De modo a medir a intensidade de cooperação na díade ao longo do tempo serão levantados os tratados bilaterais e multilaterais assinados e ratificados por Chile e Uruguai entre 1973 e 2000, disponíveis no acervo online da Biblioteca Del Congreso Nacional de Chile ${ }^{9}$. Após, realizar-se-á pesquisa documental onde serão categorizadas as áreas temáticas e o modelo de cooperação dos tratados (bilateral ou multilateral). Enfim, em ordem a julgar a intensidade de cooperação nos dois períodos destacados (1973-85; 1990-2000), será comparado o número de tratados firmados, as áreas temáticas onde se estabeleceram os acordos e o modelo de cooperação adotado, bilateral ou multilateral.

\section{3 - Análise}

\subsection{Variável Independente: Instituições Políticas Domésticas}

\subsubsection{Uruguai}

Desde o fim da ditadura de Gabriel Terra em 1938 até o ano de 1973 repetia-se não haver paralelo sul-americano ao quadro político-social de Uruguai. Como destaca Amigues (2007:90) se predominou no país uma espécie de utopia democrática, uma ilusão de estar a salvo das intempéries políticas vividas por seus vizinhos. Respeito ao estado de direito, divisão de poderes e garantias constitucionais à ampla gama de liberdades civis e políticas configuram o país como democracia em termos do Polity IV no período assinalado (ver gráfico 1). O autogolpe de Juan María Bordaberry em junho de 1973, entretanto, rompe com 30 anos de predomínio de instituições políticas democráticas, abrindo parênteses de repressão e censura que se fecha somente em 1985 (Amigues, 2007:98).

GRÁFICO 1 - Transição de regimes no Uruguai, 1946-2013 (Polity IV Project, Center for Systemic Peace)

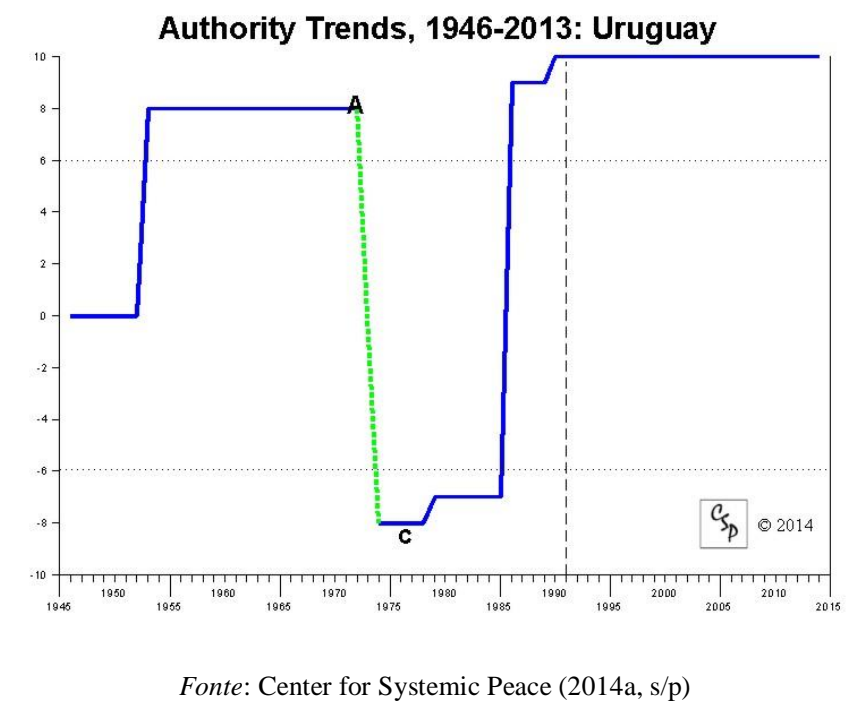

Legenda: Índice Polity IV: Democracia plena (10), Democracia (6 a 9), Anocracia aberta (1 a 5), Anocracia fechada (-5 a 0), Autocracia (-10 a -6); Linha verde: transição política; A: auto-golpe; C: golpe de Estado

9 Ver Búsqueda de Tratados, Biblioteca del Congreso Nacional de Chile: https://www.leychile.cl/Consulta/buscador_tratados 
Busquets e Delbono (2016:76-77) destacam que o autogolpe de Bordaberry marca o clímax de um processo maior de deterioro das estruturas político-institucionais uruguaias iniciado ainda no termo presidencial de Jorge Pacheco Areco em 1967 e que se subdivide em três fases. A coexistência entre 1967 e 1971 de mecanismos e instituições democráticas e de disposições de exceção ratificadas pelo legislativo, como as Medidas Prontas de Seguridad de 1967. A intensificação de medidas de exceção entre 1971 e 1972, a partir da aprovação do Estado de Guerra Interno e da Ley de Seguridad del Estado. Enfim, após sublevação de parte das forças armadas em fevereiro de 1973, tem-se a institucionalização do Consejo de Seguridad Nacional (COSENA) como conselho assessor ao Executivo e, em junho, quando da negativa pelo Senado de cassar o mandato do senador Enrique Erro a pedido da Justiça Militar, se resolve pela dissolução do parlamento, suspensão das atividades políticas e dissolução de partidos e organizações vinculadas a esquerda.

Dessa maneira, a partir de 1973, com a criação do COSENA e a dissolução do parlamento desaparecem grande parte dos constrangimentos institucionalizados ao exercício do poder por parte do executivo e também a divisão dos poderes (Busquets e Delbono, 2016:78). Quadro que se intensifica a partir de 1976 quando da suspensão das eleições gerais programadas para o ano pelo ato institucional número 1 e consumação da ruptura militar pelo ato institucional número 2, responsável por criar novo Ministerio de Justicia e Consejo de la Nación (Busquets e Delbono, 2016:82). Na nova ordem o Consejo de la Nación (formado pelo Consejo del Estado e pela Junta de Oficiales Generales) seria o órgão responsável por designar os membros e controlar grande parte das estruturas institucionais uruguaias. Por exemplo, decidiria pelo presidente da República, os membros da Suprema Corte de Justicia, do Tribunal Contencioso Administrativo e da Corte Electoral (Caetano e Rilla, 1987:63).

Em relação as instituições e procedimentos pelos quais os indivíduos podem expressar suas preferências e a existência de garantias constitucionais as liberdades civis e políticas, tem-se também deterioro da situação no Uruguai desde 1973. A repressão instaurada caracterizou-se em especial pela suspensão das eleições, censura à imprensa, perseguições políticas, detenções sem julgo e emprego da tortura, restrição aos direitos de reunião e organização política, etc. (Caetano e Rilla, 1987:24), o que evidencia as restrições a plena participação política e as liberdades individuais. Destaca Busquest e Delbono (2016:78) que em um primeiro momento foi dissolvida a Convención Nacional de Trabajadores, foi suspendido o movimento sindical, interviu-se em universidades (como a Universidad de la República) e partidos e organizações de esquerda (como o Partido Comunista, o Partido Socialista a Unión Popular, o Movimiento 26 de Marzo, dentre outros) foram submetidos a ilegalidade. Além disso, a partir de 1973 e em especial entre os anos 1975 e 1978, há o aumento paulatino da repressão, com a reclusão de presos políticos, a censura a veículos de imprensa (foram fechados, por exemplos, os jornais Marcha e Ahora), a proibição da exibição de filmes e músicas, a adoção da tortura como instrumento de Estado e a coordenação das ações repressivas com as demais ditaduras sul-americanas (Busquest e Delbono, 2016:83; Caetano e Rilla, 1987:27-28).

No ano de 1977, em vista a consolidação das instituições políticas e da nova ordem militar construída desde Bordaberry, as forças armadas anunciam no Cónclave de Santa Tereza medidas para delinear os caminhos de uma abertura política prudente (prudente apertura). Esta passava pela aprovação via plebiscito de uma nova constituição que daria maior legitimidade as mudanças estabelecidas pelos Atos Institucionais (González, 1983:64). A esse respeito, sublinham Caetano e Rilla (1987:68), Corbo (2007: 31) e Busquets e Delbono (2016:84), a tentativa do governo de legitimar o regime através das urnas, julgando suporte massivo e consensual da sociedade civil. No entanto, como destaca González (1983:64) em novembro de 1980 o "não" venceu como 57\% dos 
votos a despeito das restrições a campanha de oposição, dando início a processo de abertura política de maneira inesperada pelos militares.

Corbo (2007:27), subdivide o processo de abertura política e redemocratização uruguaia em duas etapas: i) ditadura de transição (1980-84); ii) transição democrática (1985-89). O que se evidencia pelos saltos no índice Polity IV respectivamente nos anos 1985 e 1990 (ver gráfico 1). A primeira etapa é aberta em 1980 pela vitória do "não" no plebiscito constitucional, na medida em que o projeto de poder das forças armadas perdeu força e se abriu a possibilidade de abertura política negociada (Corbo, 2007:31). Para tanto, em 1982 foram liberadas as atividades de agremiações político partidárias - apesar de partidos como o Partido Comunista e o Partido Demócrata Cristiano terem permanecido na ilegalidade por suas "vinculações ideológicas de tipo internacional" (Rial, 1990:15) - que seriam responsáveis por liderar as negociações com a junta militar, destaque para os tradicionais partidos Blanco e Colorado e para a Unión Cívica. Como resultado das negociações Del Parque Hotel (maio-junho de 1983) e del Club Naval (julho-agosto de 1984) acordou-se a realização de eleições em novembro de 1984 de modo a eleger governo civil, embora não se tenha previsto apreciação de questões relacionadas aos direitos humanos, à liberação de presos políticos e tenha-se proscrito a participação de cerca de 5.000 pessoas ao pleito eleitoral (Corbo, 2007:34-36).

Julio Sanguinetti torna-se então em novembro de 1984 o primeiro presidente civil democraticamente eleito desde o autogolpe de 1973, assumindo o país em março do ano seguinte com a árdua missão de consolidar as instituições democráticas. Entre os desafios ao seu governo, destacam-se

a anistia aos presos políticos, restituição e reparação aos funcionários públicos destituídos, repatriação de emigrados, denúncias e pedido de investigação sobre as violações aos direitos humanos durante a ditadura militar, restabelecimento das liberdades e das instituições e normas do Estado de direito e gestão da política externa (Corbo, 2007:39) ${ }^{10}$.

Como destaca Corbo (2007:39), entre o temor daqueles que se foram e a impaciência daqueles que chegaram o Uruguai de Sanguinetti paulatinamente caminhou em direção a consolidação democrática. Se por um lado fora aprovada, não sem protestos, a Ley de Caducidad que garantia anistia aos militares, por outro, foram restituídas as liberdades civis e políticas e retirados da ilegalidade agremiações como o Partido Comunista e o Partido Demócrata Cristiano, facilitou-se o retorno de exilados e foi aprovada a lei de anistia aos presos políticos (Rilla, 2008:65). Dessa maneira, quando da eleição de Luis Alberto Lacalle em 1989, pareciam estar restauradas as instituições democráticas e estar encerrado de forma definitiva o capítulo militar na história do Uruguai (ver gráfico 1) (Corbo, 2007:40).

\subsubsection{Chile}

Como pode ser observado no gráfico 2, o Estado chileno até o ano de 1973 caminhou no limiar da democracia. Aponta Vergara (1983:66-67) para o fato deque suas instituições de caráter representativo permitiam a sociedade civil articular seus interesses por meio do jogo político. A liberdade de se associar a agremiações políticas e de concorrer às eleições livres, abertas e regulares garantiam o acesso ao poder político as distintas classes e grupos e a existência de checks and

10 “...amnistía para los presos politicos y sociales, restitución y reparación funcional de empleados públicos destituidos, repatriación de emigrados, denuncias y reclamos de investigación sobre violaciones a los DDHH cometidos durante la dictadura, restablecimiento de un clima general de libertades, restablecimiento de instituciones y normas a un Estado de Derecho pleno, gestión de la deuda externa" (Corbo, 2007: 39), tradução livre. 
balances entre os distintos órgãos do governo permitia o controle das ações do executivo. $\mathrm{O}$ golpe de Estado em 1973, no entanto, transforma qualitativamente a estrutura institucional chilena. Indica Weeks (2001:69) o fato de Pinochet declarar abertamente a necessidade de criar nova ordem institucional no Chile, onde o poder executivo não encontra contrapesos e o regime representativo cai por terra, tendo sido desarticulados partidos e organizações e suprimidos os direitos e liberdades civis da população (Vergara, 1983:67-68).

Do ano de 1973 até o fim da década de 1990, assim como no caso uruguaio, desaparecem no Chile grande parte dos constrangimentos institucionalizados ao exercício do poder por parte do executivo e também a divisão dos poderes. A Junta Militar que assume o poder em 11 de setembro passa a acumular em si o exercício do executivo, legislativo e judiciário e o poder é progressivamente personalizado na figura de Pinochet (Vergara, 1983:90). Como destaca Vergara (1983:90) somente nos primeiros seis meses de regime a junta militar ditou por volta de 350 decretos leis que, junto com as atas constitucionais de 1976 e 1977, paulatinamente deixaram de lado a constituição instituída desde 1925. De qualquer maneira, sua derrogação completa terá lugar somente no plebiscito de 1980, quando da institucionalização ipso facto do regime militar (Weeks, 2001: 69).

\section{GRÁFICO 1 -Transição de Regimes Chile, 1946-2013 (Polity IV Project, Center for Systemic Peace)}

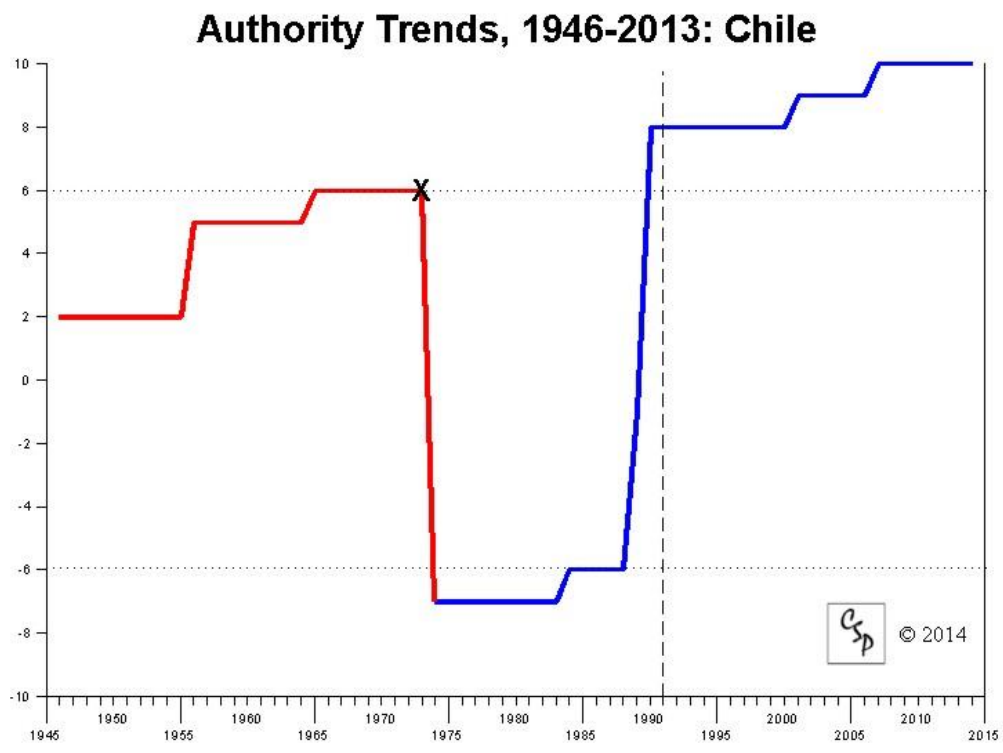

Fonte: Center for Systemic Peace (2014b, s/p)

Legenda: Índice Polity IV: Democracia plena (10), Democracia (6 a 9), Anocracia aberta (1 a 5), Anocracia fechada (-5 a 0), Autocracia (-10 a -6); Linha vermelha: período faccioso; X: Recuo Autocrático

Em relação às instituições e procedimentos pelos quais os indivíduos podem expressar suas preferências e a existência de garantias às liberdades civis e políticas, o périplo uruguaio é também acompanhado pelo Chile a partir de 1973. O regime militar declarou já em novembro desse ano a caducidade dos registros eleitorais e declarou ilegais as agremiações e partidos de esquerda e diversos movimentos políticos, postura posteriormente legitimada em ata constitucional de 1977 (Vergara, 1983:91). Além disso, as organizações sindicais perderam a autonomia e a liberdade, seus líderes foram substituídos, a Central Única de Trabajadores foi banida e o direito a greve 
suspendido até 1979 quando da entrada em vigor do Plan Laboral del Gobierno (Vergara, 1983: 92); os meios de comunicação de massa e o sistema educativo passaram a ser controlados de maneira direta ou indireta pelo regime, que "suprimiu o direito de expor e divulgar sem censura idéias e opiniões consideradas pelo governo como 'de origem estrangeira', 'dissociadoras' ou que atentassem contra a Segurança Nacional" (Vergara, 1983:98) ${ }^{11}$; e a perseguição a oposição tornouse política de governo, o que levou lideranças políticas e intelectuais a serem taxadas de dissidentes e inimigos, sofrendo represália facultada aos militares pelo regime de exceção em vigor (Chaparro e Cumplido, 1983:27-28; Vergara, 1983:93).

Em paralelo ao caso uruguaio, em julho de 1977 Pinochet anuncia no Chile projeto político de longo prazo para institucionalização e legitimação da nova ordem construída a partir do golpe de 1973 (Arcaya, 1999:86-87). Buscou-se elaborar projeto de constituição a ser submetido a plebiscito em 1980 que consolidaria ordem e instituições autoritárias, de modo a legitimar a ação sem freios ou contrapesos do regime diante a sociedade civil (Arcaya, 1999:87; Garretón, 1983:10-11). Ao fim e ao cabo, à época o projeto de transição autoritária (e não a constituição em si, prevista a ser submetida a novo pleito popular oito anos depois) sai vencedor do plebiscito e "entrega a Pinochet mandato presidencial de oito anos com grandes poderes pessoais e a Junta Militar o controle do legislativo (Garretón, 1983:7²; Santos, 2015:4), mesmo que ao longo da década de 1980 o movimento democrático passa paulatinamente a ganhar força se utilizando da ordem política vigente em vistas a transformá-la desde seu interior (ver no gráfico 2 pequeno salto no índice do Polity IVentre 1983 e 1988) (Arcaya, 1999:89-93).

Cume desse processo é a derrota do projeto político militar em novo plebiscito realizado em 5 de outubro de 1988 (Arcaya, 1999:93), ao qual Garretón (1991:107) atribui o começo de processo de transição democrática que mesmo dentro dos prazos propostos pelo regime em 1980, se desenvolve com mudanças significativas àquele pretendido por Pinochet. O setor duro da junta militar se tornou isolado e teve início às negociações para uma transição política consensuada (Arcaya, 1999:94). Das negociações entre o governo e a Concertación de los Partidos por la Democracia chega-se a consenso sobre reformas constitucionais ${ }^{13}$ a serem postas em prática e que quando aprovadas em 30 de julho de 1989 e em conjunto com a eleição de Patrício Alwyn em 14 de dezembro colocariam fim ao regime militar chileno (ver gráfico 2) (Santos, 2015:24).

\subsection{Variável dependente: Cooperação Internacional}

De modo a analisar de forma comparativa a cooperação internacional na díade ChileUruguai entre os períodos de 1973-85 e 1990-2000 foram levantados e categorizados todos aqueles tratados assinados e ratificados pelos dois países no período e disponíveis no acervo online da Biblioteca del Congreso Nacional de Chile. Em termos brutos foram recolhidos para análise 47 tratados, sendo 28 bilaterais e 19 multilaterais, girando em torno de diferentes áreas temáticas,

\footnotetext{
11 “....se suprimió el derecho a exponer y divulgar sin censura previa ideas u opiniones consideradas por el gobierno como 'de origen foráneo', 'disociadoras' o 'atentatorias contra la Seguridad Nacional', (Vergara, 1983:98), tradução livre.

12 “...entregaba al general Pinochet un mandato presidencial de ocho años con grandes poderes personales y encargaba a la junta de gobierno la tarea legislativa” (Garretón, 1983:7), tradução livre..

${ }^{13}$ A respeito, Santos (2015:24) destaca as principais reformas acordadas: “...o primeiro mandato presidencial seria de quatro anos; Reconhecimento dos recursos de amparo e proteção em estados de exceção Fim da pena do exílio; Diminuição das funções do Consejo de Seguridad Nacional, além de incorporar mais um civil, o Controlador Geral da República; Derrogação do artigo 8º; Aumento do número de senadores eleitos (de 26 para 38); A elevação à categoria de lei orgânica constitucional as normas básicas que regulam a carreira profissional dos oficiais das Forças Armadas e Carabineros"
} 
como ciência e tecnologia, energia, comércio e finanças, turismo, transporte, justiça e direito internacional, combate às drogas, esporte, dentre outras.

Em termos do número bruto de tratados, se percebe a partir do quadro 1 que mais acordos foram firmados no primeiro período (quando a díade era autocrática) do que no segundo período (quando a díade se tornou democrática), respectivamente 26 e 19 tratados. De forma mais aprofundada, pode-se adicionar a análise também o índice de tratados/ano para os dois períodos, na devida ordem $2.2 \cong$ e 1.9 (ver quadro 1). Nota-se então, que não só no primeiro período foi maior o número de acordos, como também o índice tratados/ano permaneceu relativamente constante para os dois intervalos de tempo. Resultado que em grande medida se contrapõe ao esperado inicialmente ao levar-se em conta a hipótese de trabalho. De forma a corroborá-la a expectativa era a de que o número bruto de acordos e o índice tratados/ano no segundo período fosse consideravelmente maior que no primeiro.

QUADRO 1 - Quadro comparativo entre os tratados firmados por Chile e Uruguai entre os períodos de 1973$85,1986-89$ e $1990-2000$

\begin{tabular}{|c|c|c|c|}
\hline Período & $\begin{array}{l}1973 \text { a } 1985 \text { (díade } \\
\text { autocrática) }\end{array}$ & $\begin{array}{l}\text { 1990-2000 (díade } \\
\text { democrática) }\end{array}$ & $\begin{array}{c}1986 \text { a } 1989 \text { (díade } \\
\text { mista) }\end{array}$ \\
\hline $\begin{array}{l}\text { Número de } \\
\text { tratados }\end{array}$ & 26 tratados & 19 tratados & 2 tratados \\
\hline Tratados/ano & $2.2 \cong$ & 1.9 & 0.5 \\
\hline \multirow{16}{*}{ Issue-áreas } & Justiça e Direito Internacional & Comércio e Finanças (4) & Aviação Civil (1) \\
\hline & & Ciência e Tecnologia (3) & Comércio e Finanças \\
\hline & Transporte (4); & Turismo (2) & \\
\hline & Agropecuária (2); & Combate às drogas (1) & Total: 2 \\
\hline & Comércio e Finanças (2); & Compromisso democrático & \\
\hline & Energia (2); & & \\
\hline & Meios de Comunicação (2); & Esporte (1) & \\
\hline & Turismo (2) & Integração Física (1) & \\
\hline & Administração Pública (1) & Facilitação Diplomática (1) & \\
\hline & Ciência e Tecnologia (1) & Fitossanidade (1) & \\
\hline & Combate às drogas (1) & Seguridade Social (1) & \\
\hline & Facilitação Diplomática (1) & Transporte (1) & \\
\hline & Seguridade Social (1) & Total: 11 & \\
\hline & Setor Florestal (1) & & \\
\hline & Sismologia (1) & & \\
\hline & Total: 14 & & \\
\hline \multirow[t]{2}{*}{ Modalidade } & Bilateral (20) & Bilateral (8) & Bilateral (0) \\
\hline & Multilateral (6) & Multilateral (11) & Multilateral (2) \\
\hline
\end{tabular}

Fonte: Elaboração própria 
Em relação às issue-áreas, da mesma forma em que o número bruto de tratados e apesar dos números serem bastante próximos, verifica-se que mais áreas temáticas são abarcadas no primeiro período (quando a díade era autocrática) do que no segundo período (quando a díade se tornou democrática), respectivamente 14 e 11 (ver quadro 1). Entre 1973 e 1985 predominam-se acordos em torno de Justiça e Direito Internacional (5), Transporte (4) e Agropecuária, Comércio e Finanças, Energia, Meios de Comunicação e Turismo (2) (ver quadro 1). Já entre 1990 e 2000, é predominante tratados ao redor de Comércio e Finanças (4), Ciência e Tecnologia (3) e Turismo (2) (ver quadro 1). Destaca-se, ainda, a sobreposição relativa de temas entre os dois períodos, tendo 7 destes - transporte, comércio e finanças, turismo, ciência e tecnologia, combate às drogas, facilitação diplomática e seguridade social - estado presente em ambos os momentos (ver quadro 1). Dessa forma, uma vez mais os dados não corroboram a hipótese de trabalho inicialmente delineada. Esperava-se que no ínterim no qual a díade fosse democrática os dois países tivessem cooperado em um número de issue-áreas significativamente maior do que naquele no qual a díade fosse autocrática. No entanto, mesmo tendo o número de áreas temáticas se mantido relativamente constante, o resultado encontrado não foi esse.

Quanto à modalidade da cooperação, observa-se que de forma significativa mais tratados bilaterais do que multilaterais foram firmados no primeiro momento (quando a díade era autocrática) se comparado ao segundo momento (quando a díade se tornou autocrática), na devida ordem 20 bilaterais versus 6 multilaterais e 8 bilaterais versus 11 multilaterais (ver quadro 1). A modalidade de cooperação, entretanto, no que concerne à díade em estudo, pode não ser significativa para testar o argumento desenhado na hipótese, já que especificamente a partir da década de 1990 tem-se a intensificação do multilateralismo à nível regional, por exemplo pela fundação de organizações regionais como o Mercosul. Com a intensificação do multilateralismo à nível regional, era de se esperar que comparativamente mais tratados multilaterais fossem firmados no segundo período do que no primeiro período. Temos, portanto, uma variável em nível regional potencialmente influenciando de maneira expressiva a modalidade de cooperação e, assim, ofuscando o papel das instituições políticas domésticas na questão.

Por fim, no que se trata ao período em que a díade era mista (1986-89), verifica-se que não só o número bruto de acordos e o número de issue-áreas é menor do que quando a díade era democrática e/ou autocrática - o que de certa maneira era de se esperar pelo curto período de tempo em que a díade se manteve mista -, como o índice tratados/ano é 3 vezes menor, marcando 0.5 (ver quadro 1). O que fortalece em partes (já que o tempo é realmente curto) o argumento proposto por Leeds (1999:991) de que díades mistas tendem a apresentar menores níveis de cooperação do que díades nas quais os Estados possuem instituições políticas domésticas semelhantes. Isto é, no presente estudo de caso de fato quando as díades eram similares no que tange as instituições políticas domésticas o nível de cooperação internacional foi maior de que quando a díade era mista, o que se pode observar especificamente a partir do índice tratados/ano (ver quadro 1).

\section{Considerações Finais}

Propôs-se neste artigo análise comparativa dos níveis de cooperação na díade ChileUruguai em dois momentos distintos: entre 1973 e 1985, quando a díade era autocrática, e entre 1990-200, quando a díade se tornou democrática. A partir do estudo de caso se pretendeu testar a hipótese de que as Instituições Políticas Domésticas podem explicar o nível de cooperação internacional em uma díade. Findada a análise, chegou-se a conclusão de que a hipótese não foi corroborada no caso em tela, o que de fato a enfraquece, apesar de não ser possível somente por este estudo de caso refutá-la de forma contundente e definitiva. 
De forma comparativa não houve mudanças significativas no nível de cooperação na díade nos dois períodos assinalados, como observado durante a análise, o índice tratados/ano permaneceu relativamente constante. Mais além, no primeiro período (quando a díade era autocrática) maior foi o número bruto de tratados e o número de áreas temáticas abrangidas do que no segundo período (quando a díade se tornou democrática), respectivamente 26 versus 19 e 14 versus 11 . Há que se destacar também, entretanto, que no curto período onde a díade se manteve mista (1986-89) realmente o nível de cooperação diminuiu se comparado àqueles nos quais as instituições políticas domésticas eram equivalentes, o que pôde ser visto especialmente pelo índice de tratados/ano 3 vezes menor.

Em termos de pesquisas futuras, acredita-se ser necessário realizar um maior número de estudos de caso para que se possa chegar a conclusões mais acertadas e definitivas em relação a hipótese delineada. Enfim, no que diz respeito à contribuição do artigo para as Relações Internacionais, no geral, e para a Análise de Política Externa, em particular, se entende significativo o emprego de abordagem teórica que relaxa o pressuposto do Estado unitário ordinariamente investido nas tradicionais análises neo-neo. Foi indicado a partir do desenho de pesquisa delineado a possibilidade de se adicionar às análises variáveis explicativas em nível doméstico para a compreensão de fenômenos em nível internacional.

\section{Bibliografia}

AMIGUES, F. (2007). La utopía de la democracia en Uruguay: entre la nostalgia del pasado y el desmentido de la historia, en América Latina Hoy, 47, pp. 87-99

ARCAYA, O. (1999). La transición chilena a la democracia pactada, en Estudios Políticos, 74, pp. $79-106$

BUSQUETS, J. M.; DELBONO, A. (2016). La dictadura cívico-militar en Uruguay (1973-1985): aproximación a su periodización y caracterización a la luz de algunas teorizaciones sobre el autoritarismo, en Revista de la Facultad de Derecho, 41, pp. 61-102

CAETANO, G.; RILLA, J. (1987). Breve historia de la dictadura, Ediciones de la Banda Oriental, Montevideo

CENTER FOR SYSTEMIC PEACE (2014). Polity IV Individual Country Regime Trends, 19462013: Uruguay, [S.I]: Polity IV Project. Disponível em: http://www.systemicpeace.org/polity/uru2.htm. Acesso em: 11 mai. 2018

CENTER FOR SYSTEMIC PEACE (2014). Polity IV Individual Country Regime Trends, 19462013: Chile, [S.I]: Polity IV Project. Disponível em: http://www.systemicpeace.org/polity/chl2.htm. Acesso em 23 abr. 2018

CHAPARRO, P.; CUMPLIDO, F. (1983). El proceso de toma de decisiones en el contexto políticomilitar-autoritario chileno: estudio de dos casos, em GARRETÓN, M. A. (org.). Chile 1973-198?, FLACSO, Santiago de Chile 
CORBO, D. (2007). La transición de la dictadura a la democracia en Uruguay, em Humanidades, a.VII, 1, pp. 23-47

COWHEY, P. (1993). Domestic institutions and the credibility of international commitments: Japan and the United States, em International Organization, 47 (2), pp. 299-326

FEARON, J. (1994). Domestic Political Audiences and the Escalation of International Disputes, em The American Political Science Review, 88 (3), pp. 577-592

GARRETÓN, M. A. (1983). Modelo y proyecto político del régimen militar chileno, em GARRETÓN, M. A. (org.). Chile 1973-198?, FLACSO, Santiago de Chile

GARRETÓN, M. (1991). La redemocratización política en Chile: transición, inauguración y evolución, em Estudios Públicos, 42, pp. 101-133

GAUBATZ, K. (1996). Democratic states and commitment in international relations, em International Organization, 50 (1), pp. 109-139

GEORGE, A.; BENNETT, A. (2004). Case studies and theory development in the social sciences, MIT Press, Cambridge/London

GONZÁLEZ, L. (1983). Uruguay, 1980-1981: an unexpected opening, em Latin American Research Review, 18 (3), pp. 63-76

KEOHANE, R. (1984). After Hegemony, Princeton University Press, Princeton

LEEDS, B. (1999). Domestic Political Institutions, Credible Commitments, and International Cooperation, em American Journal of Political Science, 43 (4), pp. 979-1002

MARSHALL, M.; GURR, T.; JAGGERS, K. (2017). Polity IV Project - Political Regimes and transitions, 1800-2016: Dataset users' manual [online], Center for Systemic Peace. Disponível em: http://www.systemicpeace.org/inscr/p4manualv2016.pdf. Acesso em 19 abr. 2018

MCDONALD, V. L. (2010). Before-and-After case study design, em MILLS, A.; EUREPOS, G.; WIEBE, E.(eds.). Encyclopedia of Case Study Research, SAGE Publications Inc., Thousand Oaks

MILNER, H. (1997). Interests, institutions, and information: domestic politics and international relations, Princenton University Press, New Jersey

PRZEWORSKI, A.; TEUNE, H. (1970). The Logic of Comparative Social Inquiry. Wiley Interscience, Nova Iorque

PUTNAM, R. (2010). Diplomacia e Política Doméstica: a lógica dos jogos de dois níveis, em Revista de Sociologia Política, 18 (36), pp. 147-174

RIAL, J. (1990). Los partidos políticos uruguayos en el proceso de transición hacia la democracia, S.1 [online]: Kellog Institute for International Studies, (Working Paper \#145). Disponível em: https://kellogg.nd.edu/sites/default/files/old_files/documents/145_0.pdf. Acesso em 18 jun. 2018

RILLA, J. (2008). Uruguay, 1985-2007: restauración, reforma, crisis y cambio electoral, em Revista Nuestra América, 6, pp. 63-95

SANTOS, E. dos (2015). A transição chilena e a 'constituição de Pinochet': a busca de consensos em 1989, em Revista Contemporânea, a.5, 7 (1), pp. 2-28

SARTORI, G. (1994). Comparación y Método Comparativo, em SARTORI, G.; MOLINO, L. (orgs.). La comparación en las ciencias sociales, Trad. Juan Russo e Miguel A. Ruiz de Azúa, Alianza Editorial, Madrid 
Cuadernos de Política Exterior Argentina (Nueva Época), 128, diciembre 2018, pp. 67-82

ISSN 0326-7806 (edición impresa) - ISSN 1852-7213 (edición en línea)

VERGARA, P. (1983). Las transformaciones del Estado Chileno bajo el régimen militar, em GARRETÓN, M. A. (org.). Chile 1973-198?, FLACSO, Santiago de Chile

WEEKS, G. (2001). Democratic Institutions and civil-military relations: the case of Chile, em Journal of Third World Studies, 18 (1), pp. 65-85 